\title{
O jornalismo literário e a academia no Brasil: fragmentos de uma história
}

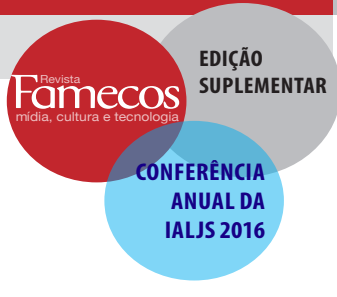

\section{Literary journalism and academia in Brazil: fragments of a history}

\section{Edvaldo Pereira Lima}

Professor Doutor da Escola de Comunicações e Artes da Universidade de São Paulo (USP). Diretor, coordenador e professor do Curso de Pós-Graduação em Jornalismo Literário, epl, único do gênero no país, administrado pela empresa Educação, Comunicação e Desenvolvimento Humano Ltda. <ed.pl@terra.com.br>

\section{RESUMO}

Em decorrência do sentido simbólico - e seu efeito motivador - de realização da Conferência Anual da IALJS no Brasil, em 2016, faz-se um esboço inicial de mapa histórico tentativo da presença do jornalismo literário na academia brasileira, especialmente quanto ao seu ensino na pós-graduação e na graduação. Contribui para uma amostra do estado atual da atividade nas universidades brasileiras, aceitando seu caráter provisório e incompleto, mas registrando uma memória inicial da atividade.

Palavras-chave: Jornalismo literário. Ensino. Brasil.

\begin{abstract}
The 2016 IALJS Conference held in Brazil last May conveys a symbolic meaning and contributes to place in perspective literary journalism studies - and teaching - in the academia in this country. As a result of this favourable psychological condition, this paper designs a historical draft map of this field regarding its undergraduate and graduate teaching in Brazilian colleges and universities. It contributes to show up the state of the art in this field, even though accepting its incomplete status, as a temporary and beginning record of its history in the educational environment of Brazil.
\end{abstract}

Keywords: Literary journalism. Teaching. Brazil.

A realização, em maio, na PUC-RS, da Conferência Anual 2016 da International Association for Literary Journalism Studies (IALJS), mais importante entidade devotada a esse campo na esfera acadêmica, estimula uma recuperação histórica dessa modalidade específica de jornalismo, quanto à sua presença na academia brasileira, particularmente no ensino. Permite uma leitura que começa pela sugestão de seu significado simbólico, tanto pelo fato de ter sido a primeira vez que a IALJS realiza um evento na América do Sul quanto pela incorporação, ao raciocínio que se desenvolve aqui, de duas características relevantes do próprio jornalismo literário, como estilo e escola de narrativas da vida real: a busca de significados que é o propósito-condutor de seus textos e a atenção, igualmente devotada, tanto aos aspectos factuais 
quanto aos simbólicos, nessa perseguição ao sentido das coisas na prática da história imediata centrada em pessoas, que é o coração da modalidade.

Tradição jornalística de origem no tempo paralela à forma mais conhecida de jornalismo - que vamos chamar aqui de convencional, o jornalismo apoiado na notícia, nos fatos concretos e na expressão informativa dos acontecimentos, tendo como fórmula técnica de linguagem, muitas vezes, o lide e a pirâmide invertida -, que começa a se esboçar nesse formato moderno, como o identificamos hoje, a partir da segunda metade do século XIX, tanto nos Estados Unidos quanto na Europa e no Brasil, o jornalismo literário nunca ocupou a posição de modelo predominante na mídia contemporânea, em nenhuma dessas regiões do mundo aqui mencionadas. Contudo, sempre coexistiu, intermitentemente aqui, de maneira contínua ali - com esse modelo, oferecendo sua abordagem narrativa diferenciada, tendo alcançado momentos de prestígio formidável ao longo do tempo, em alguns casos pontuais, como na fase do new journalism norte-americano das décadas de 1960 e 1970, assim como nos episódios históricos brasileiros da revista Realidade e do Jornal da Tarde paulista, nesse mesmo período.

Sua inerente característica epistemológica complexa, juntando o jornalismo - isto é, a atividade de comunicação de massa desenvolvida pela civilização contemporânea para, em tese, levantar, investigar, apurar e contar ocorrências sociais - à literatura - no sentido da arte narrativa de prosa, no caso empregada no território da não-ficção -, obrigatoriamente lhe confere uma situação conceitual algo difícil de ser enquadrada pelos critérios lineares de classificação e entendimento tanto pelas linhas teóricas predominantes de natureza conservadora e linear, na academia, quanto pela prática profissional nas redações. A falta de um enquadramento clássico - simplista, de fato - adequado, torna-o, para muitos, um patinho feio, sem identidade aparentemente bem desenvolvida. É, no fundo, uma questão de paradigma, de enquadramentos teóricos que governam, nas entranhas de suas bases epistemológicas, as definições, os princípios, os procedimentos e a prática de cada um desses distintos modelos de jornalismo.

Ambos procuram representar a realidade de maneira não ficcional. Mas o propósito inerente ao primeiro, o jornalismo convencional, é muito distinto do segundo, o literário. Essa diferença de postura básica molda a prática e responde pelo desenho e aplicação dos recursos que cada um emprega para cumprir sua função essencial, em tese. $O$ jornalismo noticioso está muito bem quando entrega ao receptor da mensagem conteúdos que dão conta de informar a realidade imediata. Esta é sua função nobre, este é seu papel fundamental, 
essa é sua promessa implícita à sociedade. A ela, em paralelo, soma-se o que poderíamos identificar como seu conteúdo opinativo. Daí a linguagem mais seca e referencial, nas notícias.

O jornalismo literário, a seu turno, coloca-se uma missão mais ambiciosa, que é a de tecer os liames de compreensão abrangente dos acontecimentos, tendo sempre como eixo as histórias humanas que lhes dão dramaticidade, no sentido narrativo. Daí a linguagem mais elaborada, pois essa compreensão almejada é oferecida não só pela clareza possível do raciocínio lógico, como adicionalmente pela imersão conjunta - do autor do texto, transportando consigo o leitor, seduzido pela arte narrativa de não-ficção - no universo simbólico e intelecto/sensorial construído pela matéria como representação de situações reais. O jornalismo literário realiza essa viagem narrativa utilizando uma série generosa de formatos distintos, incluindo-se aí o perfil, a reportagem temática, o texto de viagem, até mesmo o ensaio pessoal, apropriando-se às vezes de gêneros oriundos de outras fontes literárias, mas abraçados pelo estilo do jornalismo literário, como podem ser, às vezes, a própria biografia e o texto de memória. Não estando restrito aos meios periódicos, o jornalismo literário estende seu alcance para o território do livro-reportagem, em suas inúmeras variações de categorias.

Como todo bom romance de ficção, o bom texto de jornalismo literário cumpre a tarefa dupla de tanto contar bem uma história, quanto remeter à reflexão. Seu horizonte temporal é elástico, não se prende à atualidade restrita que impera na maior parte da produção jornalística convencional. Seu alcance é do tempo contemporâneo. Essas situações - a do enredo que desenrola sequencialmente um acontecimento, a do tema subjacente que faz o leitor contextualizar o primeiro num quadro abrangente de reflexão talvez de caráter universal, para além dos contornos circunstanciais dos fatos concretos, a do tempo estendido desde o passado distante ao momento presente - que marcam a liberdade de atuação do jornalismo literário são exemplificadas pelos primeiros livros de Svetlana Aleksiévitch, publicados no Brasil.

A Guerra Não Tem Rosto de Mulher e Vozes de Tchernobil: A História Oral do Desastre Nuclear, ambos lançados pela Companhia das Letras neste ano de 2016, obras notáveis dessa jornalista literária formidável, primeiro praticante - entre homens e mulheres - dessa arte narrativa a obter reconhecimento da estatura de um Prêmio Nobel de Literatura, que Ihe foi concedido em 2015, também ilustram o caráter multidisciplinar do jornalismo literário. Svetlana emprega com maestria elementos da história oral, mas pratica jornalismo literário, absorvendoos com pleno domínio, assim como faz parte da modalidade a incorporação de 
recursos de captação ou de tecnologia narrativa que procedem de áreas como a sociologia - o recurso da observação participante - e da literatura de ficção - o fluxo de consciência.

Essa existência pouco convencional do jornalismo literário, habitando o terreno de interconectividade intelectual entre o jornalismo e a literatura, fez com que a modalidade ganhasse denominações diversas, até que passasse a predominar essa mesma - com ressalvas e restrições, sem uma aceitação hegemônica -, ficando limitadas a um segundo plano outras opções, como jornalismo narrativo, literatura criativa de não-ficção, literatura da realidade.

\section{O olhar acadêmico}

$\mathrm{Na}$ atividade jornalística das redações de periódicos e na produção de autores de livros-reportagem, o jornalismo literário seguiu sendo produzido por décadas, século XX adentro, sem um rigor de classificação e categorização, por parte de seus praticantes. Tendo como origem, em muitos países, a cobertura de guerra - a da Criméia entre 1853 e 1856, por William Howard Russel, correspondente de The Times inglês; a Civil, nos Estados Unidos, entre 1861 e 1865, para a qual também foi enviado Russell como um modelo de referência para seus colegas estadunidenses; a de Canudos, no Brasil, que resultou na produção pioneira de Euclides da Cunha para o jornal O Estado de S. Paulo - e as narrativas de viagem - Mark Twain lança seu The Innocents Abroad, em 1869, título sem versão publicada no Brasil -, fincou pé na reprodução da realidade social das grandes metrópoles em transformação urbana rumo à "modernidade" - como fazem os jornalistas de Chicago ainda no final do século XIX, e como igualmente abre precedentes narrativos João do Rio nas duas primeiras décadas do século $X X$-, a modalidade já tem um lugar ao sol e até mesmo gênero próprio - o perfil - na imprensa norte-americana da década de 1920, abrigada especialmente no templo narrativo que é a revista The New Yorker'.

Mesmo assim, a academia parece não Ihe dar a devida atenção até o surgimento do new journalism nos Estados Unidos, quando finalmente um de seus expoentes, Tom Wolfe, organiza uma antologia dessa efervescente fase narrativa do jornalismo literário, acrescentando alguns comentários conceituais e um certo resgate histórico, em seu livro The New Journalism, de 1973, assinado

1 Esses e outros episódios do histórico do jornalismo literário norte-americano, o primeiro a ser pesquisado sistematicamente por acadêmicos, estão presentes em obras de Norman Sims e John C. Hartsock, assim como algo em livro de Tom Wolfe. Estão também citados nos meus dois livros acadêmicos sobre jornalismo literário. Todos serão facilmente identificáveis na lista bibliográfica, ao final deste artigo. 
em conjunto com E. W. Johnson. Essa contribuição desperta interesse no mundo acadêmico, alguns anos depois, e finalmente Norman Sims e Mark Kramer lançam Literary Journalism, em 1995, ainda uma abordagem tímida, do ponto de vista acadêmico, mas mesmo assim uma obra seminal.

País onde a prática do jornalismo literário mais se consolidou, no mundo ocidental, os Estados Unidos são também a sede da proliferação - modesta, mas significativa - do interesse acadêmico pela modalidade, a partir das iniciativas desses dois pioneiros que mais conseguiram projeção para seus trabalhos.

Mark Kramer iria abrir uma linha de estímulo relevante através de seminários e eventos especializados dessa natureza primeiro na Boston University, desde o início da década de 1990, e depois em Harvard, através de seu braço acadêmico direcionado ao jornalismo, a Nieman Foundation, para onde migrou seu programa voltado à área, em 2001. Posteriormente, Kramer irá voltar à Boston University. Norman Sims, com uma longa carreira acadêmica na Universidade de Massachusetts, unidade de Amherst, iria igualmente se tornar referência inspiradora. Profissionais de novas gerações iriam embarcar nessa avenida delineada simbolicamente por esses dois pioneiros. Um desses novos pesquisadores, John S. Bak, seria um dos coordenadores da primeira conferência trans-universitária internacional de estudos de jornalismo literário na Universidade de Nancy 2, em 2006, na França, e se tornaria o presidentefundador da IALJS, ao término desse evento. Norman Sims iria se filiar à entidade e no futuro seria eleito presidente, status sob o qual viria a Porto Alegre para abrir a Conferência de 2016.

De início, a IALJS define-se com uma postura multidisciplinare um enfoque internacional, contribuindo para se afastar da tendência mal informada, em círculos acadêmicos, de que o jornalismo literário se resume ao new journalism e de que se trata de um fenômeno exclusivamente norte-americano. Através de seus eventos, suas publicações e seu estímulo formal e informal à pesquisa e divulgação acadêmica, a IALJS tem contribuído para revelar o quanto essa modalidade, de fato, está presente em países tão distintos quanto Noruega e Japão, China e Canadá, Cuba e Inglaterra, Austrália e Argentina, por exemplo.

Dez anos após sua fundação, a entidade marcou presença no Brasil vendo crescer (e contribuindo para tal) mundo afora o jornalismo literário como um campo específico e respeitável de interesse acadêmico, justificando-se até mesmo a centralização de carreiras acadêmicas exclusivamente nesse tema. No caso brasileiro, é possível que a atenção da academia ao jornalismo literário tenha começado a ocorrer de maneira não sistemática e indireta pelo interesse isolado de colegas pesquisadores, aqui e ali, pela reportagem, de um modo geral, e pela 
produção dos new journalists, de um modo mais estrito. É importante destacar o trabalho pioneiro da professora Cremilda Medina na Escola de Comunicações e Artes, da Universidade de São Paulo, que abriu uma via consistente de pesquisa e ensino do que denominou narrativas da contemporaneidade, onde me inseri, como docente dessa instituição, para desenvolver minha própria linha de produção acadêmica centrada explicitamente no jornalismo literário e no seu veículo por excelência, o livro-reportagem.

Fui movido, nessa direção, por dois fortes estímulos convergentes. No território propriamente acadêmico, inspirou-me o trabalho pioneiro de Cremilda Medina, desde meu tempo de estudante de Mestrado na USP, especialmente seus livros Notícia - Um Produto À Venda (a primeira edição é de 1978) e A Arte de Tecer o Presente (1988) assim como seu resgate histórico, junto com Paulo Roberto Leandro, da importância de João do Rio como o primeiro repórter urbano brasileiro. Igualmente inspirava-me o que se denominava então de jornalismo interpretativo, vertente da prática da reportagem que praticara meu orientador de Mestrado e Doutorado na USP, Gaudêncio Torquato, vencedor de Prêmio Esso regional de jornalismo, editor por um período de equipe especializada na Folha de S. Paulo, professor da disciplina e anfitrião da minha première como docente de jornalismo, convidando-me para seu assistente nessa disciplina, que conduzia então - anos 1980 - na Faculdade de Comunicação Social “Cásper Líbero", em São Paulo.

No campo da prática jornalística, fui picado desde menino pela mosca azul estimulante da revista Realidade, extraordinária injeção empolgante que me fazia sonhar em me tornar jornalista de textos nascidos do mergulho intenso do profissional na realidade. Já adulto, em paralelo ao início de meu Mestrado, planejei uma carreira profissional de duas vias, a acadêmica e a da prática nas redações, tornando-me especializado em aviação comercial e turismo, buscando escrever em estilo de jornalismo literário sobre essas áreas para revistas dirigidas, tanto quanto possível. Recentemente, lancei pela plataforma Clube de Autores uma antologia dessas reportagens: Por Trás do Tapete Mágico - Histórias da Aviação.

Procurando unir as duas frentes, ao me lançar nos estudos de pósgraduação em jornalismo e ao decolar minha carreira acadêmica, a intenção desde o início foi estudar o jornalismo literário, resgatando algo do new journalism e da exuberante produção narrativa de Realidade. Contudo, no final da década de 1980 e início da seguinte, o jornalismo literário estava quase morto nas redações brasileiras, um legado abandonado no ostracismo e no esquecimento, soterrado pelos modelos-referência da época, estrelas do 
jornalismo praticado no Brasil, a revista Veja e a Folha de S. Paulo de então. O único vestígio remanescente lutava para não naufragar em ilhas isoladas que eram os livros-reportagem, na sua maioria, de autoria de jornalistas estrangeiros.

Tomei o livro-reportagem como peça de resistência e ancorei minha carreira acadêmica no jornalismo literário, apostando todas minhas fichas nesse segmento. Partidário da ideia de que o papel da universidade é triplo - pesquisa, ensino, serviço à sociedade -, procurei gerar conhecimento, estimular novas gerações de amantes da modalidade e prestar serviços à comunidade externa à USP como apoio à disseminação da cultura especializada. Daí ter produzido tanto livro educativo para o público externo naquela ocasião (O que é LivroReportagem, lançado na série Primeiros Passos da então prestigiada Editora Brasiliense, em 1993) e recentemente (Jornalismo Literário para Iniciantes, Edusp, 2014), além de ter adaptado versões de minha Dissertação de Mestrado e Tese de Doutorado para livros. Páginas Ampliadas: O Livro-Reportagem Como Extensão do Jornalismo e da Literatura - Jornalismo Literário se tornaria uma obra de referência desde a primeira edição de 1993, pela Editora da Unicamp, continuando em edições sucessivas, ampliadas e atualizadas, até a mais recente, a quarta, publicada em 2009, pela Manole.

Minha atuação como pesquisador e docente de pós-graduação na USP, agregado ao Núcleo de Epistemologia do Jornalismo coordenado por Cremilda Medina, na Escola de Comunicações e Artes, acabou por servir de âncora para jovens docentes em formação que igualmente sentiam a força envolvente do jornalismo literário. Ao passar dos anos, foi-se formando um pequeno contingente de especialistas que ampliavam suas carreiras já em curso ou começavam as suas, tendo fortes eixos de conexão com essa arte narrativa da vida real. Suas Dissertações, Teses e artigos iam formando uma base intelectual brasileira de conhecimento, os estudos analíticos ampliand o o alcance intelectogeográfico, acrescentando ao foco sobre o caso norte-americano um olhar sobre a produção brasileira de jornalismo literário.

Adicionalmente, estudos desse pequeno grupo de novos pesquisadores atravessavam o território conservador da importante - mas menos ambiciosa tarefa de análise reativa de conteúdos para gerar pro-ativamente conhecimento novo próprio. Foi esse meu caminho, ao desenvolver a proposta conceitualprática do Jornalismo Literário Avançado, reapresentada em forma atualizada, mais recentemente, em artigo para a revista Inovcom, da Intercom, Memória do Futuro: Jornalismo Literário Avançado no Século XXI, publicado em duas 
partes ${ }^{2}$. Assim como foram as trilhas abertas, por exemplo, por Monica Martinez - ampliando um dos elementos do JLA, a Jornada do Herói, em sua Tese de Doutorado, sob minha orientação, que resultaria num livro voltado ao público externo - e por Sérgio Vilas-Boas, orientando, cuja Dissertação de Mestrado e cuja Tese de Doutorado igualmente se tornaram livros para o público geral³.

O caráter multidisciplinar dado à abordagem do jornalismo literário nessa atividade dinâmica que girava em torno do meu trabalho de pós-graduação, centrado em jornalismo literário, e o de Cremilda Medina, focalizado nas narrativas da contemporaneidade, permitia outras aproximações interessantes, como as de Raul Hernando Osório Vargas e Alex Criado com relação à história oral; a de José Edmundo Heráclito Silva e de Andrea de Arruda Botelho Borges, com relação à psicologia; e a de Ana Taís Martins Portanova Barros, com os estudos do imaginário.

No final da década de 1990, essa ebulição contagiosa do jornalismo literário como campo de estudo e ensino, na ECA-USP, iria transbordar para um experimento significativo, quando recebi o convite para, em paralelo à Universidade de São Paulo, dirigir o Curso de Comunicação Social da Universidade de Uberaba (Uniube), em Minas Gerais. Tradicional, apoiado pela elogiável prática de editar semanalmente, ao longo do ano letivo, seu jornal-laboratório Revelação, o curso da Uniube encontrava-se, porém, estagnado, algo preso a uma visão paroquial do jornalismo. Solicitei e obtive da reitoria carta branca para reformular totalmente o curso, modernizando seu projeto pedagógico, implementando um modelo de gestão algo inovador e flexível, contando com um corpo docente mesclado entre professores locais e convidados vindos desse grupo de entusiastas jovens que se qualificavam em nível avançado na ECA.

Pessoas que iriam, com o tempo, cravar no mundo acadêmico suas próprias bem-sucedidas carreiras, tiveram um início promissor e entusiasmado como docentes da Uniube, no período de 1998 a 2004: Monica Martinez, atualmente na Universidade de Sorocaba (UNISO); Alex Criado, no Complexo Educacional Faculdades Metropolitanas Unidas (FMU); Ana Taís Portanova Barros, na Universidade Federal do Rio Grande do Sul (UFRGS); Sérgio Vilas-Boas, por um período na academia e, mais recentemente, como escritor independente; e Raul Hernandez Osório Vargas, na Universidade de Antioquia, em Medellín (Colômbia).

2 As obras encontram-se nas Referências Bibliográficas deste texto.

3 As obras encontram-se nas Referências Bibliográficas deste texto. 
O jornalismo literário tornou-se o centro do projeto pedagógico, na habilitação jornalismo, e o Revelação seu cartão de visitas. Como parte da estratégia desenhada, tanto o jornal-laboratório quanto os livros-reportagem que passaram a ser aceitos como formatos válidos de Trabalho de Conclusão de Curso (TCC) foram inscritos em concursos e prêmios educacionais e jornalísticos nacionais, trazendo maior visibilidade ao que se fazia no Triângulo Mineiro, como experimento inovador. Um desses trabalhos, o livro-reportagem Anjos da Vida, de Mariângela Camargos, foi finalista do Grande Prêmio Ayrton Senna de Jornalismo, ano 2000. O jornal-laboratório Revelação acabou conquistando o Prêmio Top Educacional 1999, da Associação Brasileira de Mantenedoras de Ensino Superior (ABMES). Creio que esse foi o primeiro - e provavelmente é o único, até o momento - caso de posicionamento do jornalismo literário como centro de um curso de graduação em jornalismo, no país. Um feito modesto, mas histórico, em sua própria medida.

Desse grupo de pesquisadores e docentes emerge o que é, provavelmente, a mais consistente e volumosa produção acadêmica de conhecimento em jornalismo literário na academia brasileira atual, a de Monica Martinez, prolífica autora de artigos e condutora de pesquisas próprias e associadas com colegas do Brasil e do exterior. Adicionalmente, outros pesquisadores que fizeram a pós-graduação na ECA, mas não participaram do projeto em Uberaba, também têm realizado trabalhos de jornalismo literário, como Silvio Demétrio, na Universidade Estadual de Londrina.

Naturalmente que têm acontecido produções de outros colegas docentes não vinculados direta ou indiretamente a esse grupo da ECA-USP, da década de 1990 e do início dos anos 2000. São produções movidas pelo entusiasmo pessoal dos estudiosos, especialmente quando se definem pelo tema em suas Dissertações de Mestrado e Teses de Doutorado. Paulo Paniago, na Universidade de Brasília; Rogério Borges, na Universidade Federal de Santa Catarina; e Eduardo Ritter, na Pontifícia Universidade Católica do Rio Grande do Sul, são exemplos, mas certamente há muito mais casos recentes salpicados pelo país que demandariam um levantamento minucioso. Contudo, não é foco central deste artigo a produção de trabalhos acadêmicos de pesquisa em jornalismo literário na universidade brasileira, tema que está contemplado por Monica Martinez, em contribuição levada ao XXXIX Congresso Brasileiro de Ciências da Comunicação da Intercom, em setembro de 2016, em seu artigo Jornalismo Literário no Século 21: Reflexões Sobre Conceitos, História e Redes de Pesquisas. A proposta, aqui, é centrar bateria no ensino. 
Assim, entremos em outro episódio significativo, nesta nossa jornada de recuperação histórica parcial.

Durante muito tempo, no período contemplado por este artigo, o livroreportagem foi o portão de entrada do jornalismo literário também no ensino de graduação. Mesmo as instituições que não mantinham uma disciplina própria da modalidade, reservavam uma na grade curricular para o livro-reportagem ou o aceitavam como opção para o TCC. Quando a Intercom passou a premiar livros-reportagem como uma das categorias de TCC, por meio da Expocom, isso representou uma iniciativa altamente estimulante, muito bem aproveitada pela PUC-Campinas (São Paulo), graças especialmente ao trabalho hercúleo do professor Celso Falaschi, tornando essa instituição de ensino, em uma certa fase, provavelmente, a mais destacada do país, em volume, na produção de livros-reportagem como TCC e a que mais apresentava obras para concorrer ao Expocom. Superava inclusive a ECA.

Em paralelo à produção explicitamente classificada como jornalismo literário e desvinculada dos TCC, Cremilda Medina conduzia, na USP, seu projeto da série de livros-reportagem São Paulo de Perfil, escritos e editados por seus alunos de graduação - mais tarde contou também com a participação de alunos do programa Universidade Aberta à Terceira Idade -, uma notável iniciativa de histórias do cotidiano paulista, que registrava 26 volumes publicados, no levantamento feito para este artigo no portal da USP4.

Foi de Celso Falaschi a iniciativa de orientar um TCC de um grupo de alunos que consistiu na criação do primeiro site de jornalismo literário no Brasil. Após a defesa do trabalho, Celso e um dos componentes desse grupo, Rodrigo Stucchi, pensaram em criar na web um site público de jornalismo literário, convidando a mim e a Sergio Vilas-Boas para unirmos conhecimento e força na realização desse trabalho. O objetivo seria disseminar a cultura e o conhecimento da modalidade para além dos territórios acadêmicos, chegando ao público dos profissionais - jornalistas e outras categorias - que pudessem se interessar pelas narrativas de não-ficção.

Nasceu assim o TextoVivo, mantido durante alguns anos e que se tornaria, num certo momento, o maior arquivo digital brasileiro de narrativas produzidas por autores nacionais recentes, nessa modalidade. Dois anos após o lançamento de TextoVivo, Celso foi persuasivo o suficiente para estimular esse pequeno grupo a embarcar no projeto de criação do primeiro curso de pós-graduação em jornalismo literário no Brasil. Mesmo na ECA, minhas disciplinas de pós-

4 Disponível em: http://www5.usp.br/servicos/sao-paulo-de-perfil/. Acesso em: 23 ago. 2016. 
graduação, embora tratassem de jornalismo literário, essencialmente, estavam atreladas ao programa de Pós-Graduação em Ciências da Comunicação dessa Escola.

Seria um programa latu-sensu, Especialização em lugar do Mestrado, pois o intento era qualificar praticantes, e não, pesquisadores. Embalado pela ideia visionária de Celso, o grupo abraçou entusiasmado o sonho e, em 2005, conduziu a primeira versão do programa, atrelado a outros projetos de pós-graduação da Metrocamp, em Campinas (São Paulo). Encarreguei-me essencialmente do projeto pedagógico e da formação do corpo docente, para o qual convidei muitos dos colegas que haviam passado pela formação na ECA, quando não, também, pela experiência na Uniube.

Para o ano seguinte, Celso nos apresentou a ousadia de conquistarmos maior autonomia, gerando um curso próprio - e não moldado a programa já existente - totalmente novo e procurando outro parceiro institucional para as questões de credenciamento. Ao mesmo tempo, foi persuasivo o suficiente para criarmos uma entidade jurídica, uma Organização Não Governamental (ONG), que assumiria operacionalmente a condução do Curso, tomando em paralelo outras iniciativas de promoção do jornalismo literário. Surgiu assim a Academia Brasileira de Jornalismo Literário $(A B J L)$ que, além do curso - realizado durante alguns anos em Campinas, sempre em São Paulo e, também, simultaneamente em outras localidades, às vezes, como Curitiba, Porto Alegre, Goiânia e Brasília - realizaria, em 2007, a primeira Conferência de Jornalismo Literário no Brasil, com a presença de profissionais de destaque brasileiros e internacionais, e lançaria o livro Jornalistas Literários: Narrativas da Vida Real por Novos Autores Brasileiros, também em 2007, pela Summus, antologia de trabalhos de alunos da pós-graduação organizados por Sergio Vilas-Boas.

A ABJL foi extinta em 2013, os sócios-fundadores se desligaram, mas o curso continuou, desde então exclusivamente sob minha coordenação e continuando a contar basicamente com o mesmo corpo docente, acrescido de dois ex-alunos do próprio programa e de um ou outro professor novo convidado a integrá-lo de vez em quando.

Em 12 anos de realização do programa, foram qualificados mais de 300 profissionais - jornalistas e graduados em outras áreas, como Letras, Psicologia, Educação, História, Física -, resultando daí produções de jornalismo literário inseridas em veículos convencionais de imprensa, projetos independentes, livros-reportagem, iniciativas de estabelecimento de negócios próprios que fazem uso da modalidade. Alguns se dirigiram para a área acadêmica, já eram 
ou se tornaram professores universitários, outros foram cursar Mestrado ou Doutorado.

Beatriz Jucá é um exemplo de pós-graduada recente que está fazendo um ótimo trabalho de jornalismo literário, sempre que possível, no veículo em que é repórter, o Diário do Nordeste, produzindo, às vezes, séries, como a premiada pela União Nacional dos Dirigentes Municipais de Educação - Vozes do Silêncio, sendo coautora de outras, como O Quinze $(1925+2015)$ que tem como ponto de partida o romance $O$ Quinze de Rachel de Queiróz, Memórias de Cem Anos, e Corda Bamba, sobre a vida circense.

Andrea Ascenção e Samantha Silva foram igualmente vencedoras de prêmios importantes. No caso de Andrea, o perfil de um cirurgião especialista em transplantes do coração, em O Homem da Segunda Chance, conquistou um prêmio na categoria jornalismo literário, da cidade de Manaus, enquanto 1 Por Cento da Praça da Sé recebeu um prêmio do movimento Shift - Agentes Transformadores. Samantha, a seu turno, foi vencedora de um prêmio Sebrae com sua matéria Lingerie Tira Mulheres do Campo e Faz Polo Virar Realidade em Juruaia ${ }^{5}$. Ana Magalhães, Guilherme Soares Dias e Júlio Simões criaram a revista digital Calle $2^{6}$, Regina Magalhães e Fred Linardi conduzem Biografias e Profecias ${ }^{7}$, uma editora de histórias de vida e empresarias.

Bruna Vieira Guimarães, agora também professora do Curso de PósGraduação em Jornalismo Literária (chamado "epl"), empresária, emprega na sua Agência Gentecom ${ }^{8}$, quando possível, o estilo da modalidade, especialmente utilizando-se do gênero perfil em comunicação interna para clientes, assim como na produção de edições especiais comemorativas para empresas. Flávia Vasconcelos, Sibele Oliveira, Abner Laurindo, Ruth Rendeiro, Juliana Damante, Arcelina Helena Dias, Eduardo Reis, Matheus Trunk, Carla Lacerda do Nascimento, Dina Gaspar, Lelia Maria Romero, Wagner Hilário são alguns dos muitos exalunos que escreveram e publicaram livros-reportagem ou de memórias.

$\mathrm{Na}$ área acadêmica, alguns se tornaram professores universitários, outros já defenderam suas respectivas Dissertações de Mestrado ou Teses de Doutorado, como Angela Farah, doutoranda na ECA-USP, professora do Centro Universitária da Cidade de União da Vitória, no Paraná; Ben-Hur Demeneck,

5 Ambas podem ser lidas com acesso através do link. Disponível em: http://www.edvaldopereiralima. com.br/index.php/jornalismo-literario/pos-graduacao/jornalismo-literario-na-veia. Acesso em: 23 ago. 2016.

6 Disponível em: http://www.calle2.com. Acesso em: 23 ago. 2016.

7 Disponível em: http://www.biografiaseprofecias.com.br. Acesso em: 23 ago. 2016.

8 Disponível em: http://www.gentecom.br. Acesso em: 23 ago. 2016. 
doutorando pela USP, professor da Universidade Estadual de Ponta Grossa, também Paraná; Mateus luri Passos, doutor pela Unicamp; Francilene Oliveira e Bruno Pessa fizeram Mestrado na Universidade Metodista de São Paulo.

Se um dos objetivos da instituição acadêmica é disseminar conhecimento e qualificar a prática profissional, esse processo de trabalho que vem da ECAUSP, atravessa a extinta Academia Brasileira de Jornalismo Literário e continua no Curso de Pós-Graduação em Jornalismo Literário (epl), conta com sementes já florescidas na sociedade como um todo. Mas sua contribuição é apenas um capítulo nessa história recente. Vejamos outras iniciativas que nos trazem um quadro um pouco mais amplo da situação de momento no ensino da modalidade no país.

\section{Amostras de um retrato incompleto}

Este texto não tem a pretensão de oferecer um quadro pleno do ensino de jornalismo literário em graduação no Brasil, tarefa que exigiria uma pesquisa talvez morosa e sistemática. O que compartilha aqui é uma amostra informal, resultante de um levantamento espontâneo junto a colegas que responderam a um chamado recente. De qualquer modo, pontua casos que compõem parcialmente um significativo mapa atual.

Monica Martinez aborda o jornalismo literário em sua disciplina Narrativas Midiáticas, no Programa de Pós-Graduação em Comunicação e Cultura da UNISO. Também coordena a implementação de um Grupo de Pesquisas em Narrativas Midiáticas - NAMI/Uniso/CNPq - que focaliza um autor por ano e publicará, como resultado, um livro alusivo. Pesquisadora intensiva, como já apontada neste artigo, tem dado enorme contribuição para a inserção do jornalismo literário nos espaços acadêmicos. É coordenadora adjunta do Grupo de Pesquisa da Intercom de Teorias do Jornalismo e diretora científica do SBPJor, espaços onde trabalha assiduamente para essas inserções, tendo, nessa última, aberto este ano uma rede de pesquisadores em narrativas, onde se dá destaque ao jornalismo literário.

Aquinei Timóteo lidera, na Universidade Federal do Acre (UFAC), discussões sobre as intersecções entre jornalismo, narrativa, representação e literatura. Inseriu na grade curricular de graduação a disciplina jornalismo literário, orienta livros-reportagem em TCC e edita a revista Tropos, que mantém um tópico sobre a modalidade. As discussões já resultaram em um livro: Pesquisa em Comunicação: Registros, Olhares e Narrativas, lançado pela Editora AMCGuedesem 2015, do qual Aquinei foi um dos organizadores e, três dos artigos da obra, tratam explicitamente de temas da modalidade. Cursando 
doutorado na Unisinos, no momento, Aquinei pesquisa a representação das vidas de pessoas comuns no jornalismo literário e na história, tendo como objetos de estudo livros-reportagem de Eliane Brum.

$\mathrm{Na}$ Unisinos, por sinal, Thaís Helena Furtado, coordenadora do curso, informa que o novo currículo de graduação contempla a disciplina obrigatória Jornalismo Literário, conduzida por ela própria. Há um currículo antigo também em vigor, paralelamente, que contempla a modalidade, mas sob outra denominação. Os dois campi da instituição - respectivamente em São Leopoldo e Porto Alegre - trabalham a modalidade, canalizando reportagens preparadas pelos alunos para as revistas-laboratório Primeira Impressão (já na 46a edição) e Josefa ("em homenagem à primeira mulher jornalista brasileira, gaúcha de Viamão", enfatiza a colega em mensagem por e-mail), recém iniciada, agora na segunda edição.

O Rio Grande do Sul é pródigo em iniciativas dessa natureza. Na Universidade de Santa Maria (UFSM), Paulo Roberto Araújo, que tomou contato com o new journalism através de um curso de extensão promovido por Sérgio Caparelli, na PUC-RS, no início dos anos 1980, do qual também participou a colega Eunice Olmedo (já falecida, professora de enorme prestígio na UFSM), sempre trabalhou a modalidade em disciplinas de jornalismo impresso. Por um tempo, também o levou ao radiojornalismo, através do programa-laboratório $\mathrm{Na}$ Boca do Monte e do quadro Memórias da Casa Velha, conduzido com os alunos. Em 2006, criou a disciplina Jornalismo Literário (impresso) e em parceria com a colega Viviane Borelli, de Produção Gráfica, criaram a Revista proa - inicialmente edições impressa e digital, depois apenas a versão online. Deverá novamente ter uma edição impressa este semestre.

Na Universidade de Santa Cruz do Sul (UNISC), Demétrio de Azeredo Soster insere o jornalismo literário em atividades laboratoriais que incluem duas edições anuais do jornal Unicom e uma da Revista Exceção. No Programa de Pós-Graduação em Letras da UNISC, Demétrio contribui para a formação de pesquisadores que façam intersecção estreitamente relacionada ao jornalismo literário.

Por sua vez, a PUC-RS, que abrigou no seu campus de Porto Alegre o evento da IALJS e é hospedeira dessa edição especial da Revista FAMECOS dedicada ao jornalismo literário, começou a trabalhar o tema por volta de 2006, comenta Juan de Moraes Domingues, que passou a integrar o corpo docente em 2008 e a conduzir a disciplina eletiva Jornalismo e Literatura, que abraçava o tema, em 2010. Era uma disciplina aberta a estudantes de jornalismo e de outras áreas. Em 2014, com a reformulação do currículo, jornalismo literário foi 
integrada ao programa com nome próprio e status de disciplina regular. Em 2016, a criação da Agência J de Reportagem, projeto laboratorial, passou a produzir conteúdo de interesse na área de Direitos Humanos, ser distribuído semanalmente para veículos do Rio Grande do Sul, adotando preferencialmente o estilo do jornalismo literário. Juan, que é um dos editores, também orienta TCC centrados na modalidade.

Noutro extremo do país, na Universidade Federal do Pará (UFPA), Guilherme Guerreiro Neto tem trabalhado a modalidade, orientando dois TCC sobre o tema entre 2014 e 2016, e proferindo um minicurso. Comenta também em uma mesa do importante SeminárioTempos de Reportagem que deu guarida ao tema através de palestras de dois repórteres praticantes da modalidade nas regiões Norte e Nordeste: a pernambucana Fabiana Moraes e o paraense Ismael Machado.

De volta ao Sul, Criselli Montipó, pós-graduada em jornalismo literário, faz um relato que se isenta de tocar em números e fatos amplos - há outros professores além dela que abordam a modalidade na PUC-PR, em Curitiba, diz, numa correspondência por e-mail com este autor -, mas destaca um caso comovente de TCC de livro-reportagem digital que orientou. O que o Câncer Não Destrói: Relatos de Luta e Coragem, de autoria de Mônica Seolim, Fernanda Bertonha, Jaderson Policante, Márcio Luis Galan Júnior e Thamiris Mottin, contendo dez perfis de pessoas que lutam ou lutaram contra a doença. O livro segue o conceito de narrativas de transformação, formulação do autor deste artigo que procura enfatizar a prática da humanização - um dos alicerces filosóficos do jornalismo literário - e a reorientação do olhar do jornalista para um ponto mais além da simples constatação crítica de uma realidade dada. Criselli enfatiza que esse foi dos projetos mais significativos e sensíveis que orientou, por essa qualidade tão nobre da modalidade, que o TCC representou tão bem ${ }^{9}$.

9 Criseli compartilha as palavras de Mônica Seolim, palavras essas que refletem essa qualidade de humanização e o poder do jornalismo literário, sob esse conceito de narrativas de transformação que se está estimulando nas novas gerações de escritores da vida real: "Transformar uma experiência negativa e dolorosa em algo construtivo é um dos grandes desafios do ser humano. Lidar com os obstáculos que a vida impõe sem permitir que eles mudem a nossa essência e nos tornem pessoas amarguradas. A ideia de escrever esse livro está vinculada a isso: no dia 13 de agosto de 2015, momento em que as equipes do 70 período de Jornalismo da PUCPR definiam seus temas de Trabalho de Conclusão de Curso, minha mãe foi internada em um hospital de Curitiba. Sentia dores de cabeça terríveis, tinha pequenos desmaios e ainda estava completando mais de nove anos de luta contra o câncer. (...) Após perder gradativamente os movimentos, a audição de um dos ouvidos e a visão dos dois olhos, ela partiu, no dia 4 de setembro. Minha equipe de TCC é formada pelos melhores amigos que fiz durante a faculdade e todos acompanharam muito de perto esse acontecimento. Após o falecimento dela, em reunião de grupo surgiu a ideia de contar a história da minha mãe e de outras pessoas que também 
Pausa neste artigo, após esse depoimento emotivo da colega e das palavras de sua aluna na nota de rodapé.

Um espaço de três linhas de silêncio.

\section{E continuemos.}

Na PUC-Campinas, o colega professor da casa e também do Curso de PósGraduação em Jornalismo Literário (epl), Fabiano Ormaneze, pós-graduado na área, pontua que a disciplina obrigatória Jornalismo Literário foi implantada em 2001, por força do trabalho incansável de Celso Falaschi. Celso não está mais na PUC-Campinas, a disciplina continua, mantida na nova grade curricular (2012) e no novo projeto pedagógico (2016), conduzido por Fabiano. O conteúdo está direcionado tanto aos aspectos formais quando à prática de gêneros, como o perfil e a narrativa de viagem, resultando daí revistas e e-books produzidos pelos alunos. Em 2015, destacou-se a produção do projeto institucional Por Onde Andas, perfis de ex-alunos de comunicação, na celebração dos 45 anos do curso da PUC-Campinas nessa área. A clássica análise de livros-reportagem em estilo jornalismo literário também acontece, tendo o exame de Entretanto, Foi Assim Que Aconteceu, de Christian Carvalho Cruz (2011), resultado em quatro artigos acadêmicos no evento nacional da Intercom, de 2015, na Universidade Federal do Rio de Janeiro (UFRJ). Fabiano também já ministrou cursos de extensão da modalidade na PUC-Campinas, entre 2010 e 2012.

Na Universidade Federal de Goiás (UFG), Angelita Pereira de Lima ministra, desde 2006, a disciplina, no conjunto de abordagens contempladas em Jornalismo Especializado. O entusiasmo de Angelita e a reação positiva dos alunos têm resultado em muitos TCC e teve um momento especial na produção da revista-laboratório Becos Comunicantes, em 2015, toda ela - 16 matérias ao todo - em estilo de jornalismo literário.

Em São Paulo, Jaqueline Lemos aborda o jornalismo literário em duas frentes na Universidade São Judas Tadeu. Para os alunos do segundo semestre letivo, abrange teoria e prática na disciplina Processos e Técnicas de Edição em Jornalismo Impresso. Para as turmas do quarto ano letivo, trabalha livrosreportagem na disciplina Planejamento em Projetos. Só em 2015, foram elaborados 17 livros-reportagem.

tivessem lutado bravamente contra o câncer, assim como ela! Conversamos muito e concluímos que esses relatos inspiradores mereciam ser contados e que é papel do jornalista dar voz a eles". 
Nas Faculdades Integradas Rio Branco, também na capital paulista, o projeto Jornalistando, conduzido por Renata Carraro, consiste na produção de livros-reportagem abrigada pelas disciplinas Edição 2 (curriculum antigo) e Jornalismo Literário e Grande-Reportagem (novo), lançados comercialmente, depois de finda a etapa educacional, pela Editora In House. São selecionados e editados, em uma etapa final, os melhores textos. Cada livro é articulado em torno de um tema ou recorte eleito pelos alunos. Não É Aventura, É Reportagem: Jornalismo e Cobertura de Conflitos, de 2013, traça 12 perfis de jornalistas que cobrem conflitos. Em 2015, foi a vez de Jornalismos: Histórias de Uma Arte Plural, transportando os perfis de 13 jornalistas que atuam em distintas áreas.

Alex Criado, igualmente professor no Curso de Pós-Graduação em Jornalismo Literário (epl), docente de graduação no complexo educacional das Faculdades Metropolitanas Unidas - FMU, FIAM e FAAM - tem trabalhado o livro-reportagem, com ênfase em jornalismo literário, na disciplina Produtos Jornalísticos (impresso). Nos últimos cinco anos, orientou 29 livros-reportagem em TCC, destacando como resultados notáveis Persona, de Juliana Monteiro (perfis de músicos alternativos); Memórias de Uma Batalha, de Rafael Iglesias (perfis de pessoas que enfrentam o câncer); OsMeninos de 43, de Rodrigo Ramalho (perfis de jovens que viveram em torno do que é hoje a Arena Corinthians, o estádio de futebol Itaquerão); Adeus, Hiroshima, de Denise Bertola (histórias de sobreviventes da primeira bomba atômica lançada no Japão durante a II Guerra Mundial e que moram no Brasil).

Este quadro é parcial, mas creio que desenha um panorama razoavelmente aceitável de casos relevantes de abordagem do jornalismo literário no ensino brasileiro.

Se, no mercado editorial, o jornalismo como instituição, tal qual conhecemos, atravessa uma de suas piores crises, com ameaças profundas à sua identidade e função na conturbada sociedade de nosso tempo, quero crer que a crise é muito mais do modelo de negócio estabelecido do que propriamente pela demanda de narrativas de qualidade do real, existente no nosso tempo. Essa demanda é patente, aquilatável, perceptível, pelo menos em certos bolsões do mercado cultural nas grandes metrópoles. O jornalismo não está atendendo boa parte dessa demanda por ter se afastado de um dos recursos mais apropriados para responder a isso, que é a tradição do jornalismo literário, em seu legado de contar histórias com sabor estético, no sentido narrativo, e profundidade centrada em figuras humanas.

As novas gerações, em parte, continuam a responder ao chamado pelas boas histórias da vida real que atravessam todos os tempos e todos os lugares, ecoando em corações e mentes, décadas após décadas, em todos os 
momentos históricos da vida contemporânea. As instituições educacionais brasileiras, graças aos esforços de professores e pesquisadores abnegados que lutam contra os obstáculos inevitáveis, mantêm viva a chama, como possível. No cenário internacional, cresce a adesão de estudiosos ao tema, caminha para solidificar-se a área como campo digno de pesquisas acadêmicas de qualidade.

Se, de um lado, o cenário é de caos eventual, de outro, a força condutora da academia alimenta a manutenção do interesse pelo jornalismo literário que, camaleão, sustentado pela sua matriz da arte de contar histórias, poderá se adaptar - como já vem fazendo - a novos formatos e novos meios narrativos, sobrevivendo na nova civilização que poderá surgir após o crítico período atual de grandes mudanças de paradigmas, modelos e valores. Como um eventual novo mundo certamente manterá a função construtora de identidades e realidades do contar histórias, a essência do jornalismo literário - venha a ter ou não esse nome no futuro - terá presença vital nesse cenário. E a comunidade acadêmica terá cumprido seu nobre papel, nutrindo os sonhos e a evolução do talento presente potencialmente nas atuais e futuras breves gerações.

\section{REFERÊNCIAS}

ALEKSIÉVITCH, Svetlana. A Guerra não tem rosto de mulher. São Paulo: Companhia das Letras, 2016.

ALEKSIÉVITCH, Svetlana. Vozes de Tchernóbil: a história oral do desastre nuclear. São Paulo: Companhia das Letras, 2016.

CRUZ, Christian Carvalho. Entretanto, foi assim que aconteceu. Porto Alegre: Arquipélago, 2011.

HARTSOCK, John C. A History of American literary journalism. Boston e Amherst: University of Massachusetts Press, 2001.

LIMA, Edvaldo Pereira. Jornalismo literário para iniciantes. São Paulo: Edusp, 2014.

LIMA, Edvaldo Pereira. Páginas ampliadas: o livro-reportagem como extensão do jornalismo e da literatura - jornalismo literário. 4. ed. São Paulo: Manole, 2009.

LIMA, Edvaldo Pereira. Por trás do tapete mágico - histórias da aviação. São Paulo: plataforma editorial Clube de Autores. Disponível em: <https://www. clubedeautores.com.br/book/215281--Por Tras do Tapete Magico> - 2016. Acesso em: 23 ago. 2016.

LIMA, Edvaldo Pereira Lima. Memórias do futuro: Jornalismo Literário Avançado no 
século XXI. Inovcom, São Paulo, Intercom, v. 6, n. 1, p. 12-23, 2014.

LIMA, Edvaldo Pereira. O que é livro-reportagem. São Paulo: Brasiliense, 1993.

MARTINEZ, Monica. Jornada do herói: a estrutura narrativa mítica na construção de histórias de vida em jornalismo. São Paulo: Annablume e Fapesp, 2008.

MEDINA, Cremilda. A Arte de tecer o presente: narrativa e cotidiano. São Paulo: Summus, 2003.

MEDINA, Cremilda. Notícia: um produto à venda. São Paulo: Summus, 1988.

SIMS, Norman. True stories: a century of literary journalism. Evanston: Northwestern University Press, s/d.

SIMS, Norman e Mark Kramer (Ed.). Literary journalism. Nova York: Ballantine, 1995.

VILAS-BOAS, Sérgio. Biografismo: reflexões sobre as escritas da vida. São Paulo: Unesp, 2014.

VILAS-BOAS, Sérgio. Perfis - o mundo dos outros - $\mathbf{2 2}$ personagens e 1 ensaio. São Paulo: Manole, 2014.

VILAS-BOAS, Sérgio. (Org.) Jornalistas literários - narrativas da vida real por novos autores brasileiros. São Paulo: Summus e ABJL, 2007.

WOLFE, Tom; E. W. Johnson. The new journalism. Londres: Picador, 1973.

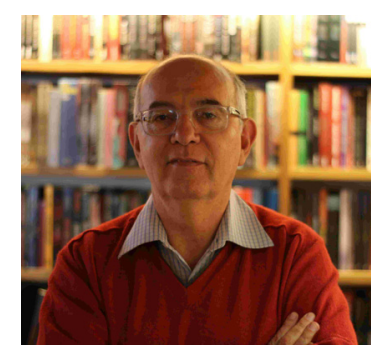

Recebido em: 25/8/2016

Aceito em: 25/8/2016

Edvaldo Pereira Lima <ed.pl@terra.com.br>

Curso de Pós-Graduação em Jornalismo Literário, epl.

Rua Alberto Nascimento Jr., 178, b. 3, apto. 21

CEP 05595-040 São Paulo - SP 